\title{
arte agora: partilhas de matérias
}

\author{
Eleonora Fabião ${ }^{1}$, Adriana Schneider Alcure $^{2}$
}

Resumo: O encontro internacional arte agora: partilhas de matérias, evento acadêmico realizado pelo Programa de Pós-graduação em Artes da Cena UFRJ, foi concebido como um programa performativo. Neste evento-experimentação, apresentações de falas individuais foram substituídas por diálogos inspirados pelas matérias que as/os participantes trouxeram para partilhar. Agentes humanos e não-humanos reuniram-se em pensamento e ação.

Palavras-chave: arte e política; programa performativo; cena expandida; eventos acadêmicos

\section{art now: sharing matters}

\begin{abstract}
The international encounter art now: sharing matters, organized by the Arts of the Scene Postgraduate Program at UFRJ, was an academic event conceived as a performative program. In this experimental event, the presentations of individual talks were replaced by dialogues between participants inspired by matters each had brought to share. Human and nonhuman agents gathered in thought and action.
\end{abstract}

Keywords: art and politics; performative program; expanded scene; academic events.

1 É performer e teórica da performance. Professora da Universidade Federal do Rio de Janeiro, Escola de Comunicação - Pós-graduação em Artes da Cena e Graduação em Direção Teatral. Mestre em História Social da Cultura (PUCRio) e Mestre e Doutora em Estudos da Performance (New York University). Realizou pós-doutoramento na New York University. É bolsista de produtividade em pesquisa nível 2 do CNPq. E-mail: ef383@nyu.edu; Instituição filial: Universidade Federal do Rio de Janeiro; País: Brasil.

2 É atriz, diretora e pesquisadora de teatro. Professora do Curso de Direção Teatral e do Programa de Pós-Graduação em Artes da Cena, da Escola de Comunicação, da UFRJ. Realizou pesquisa de pós-doutorado na Universität Bonn com bolsa do Programa Capes / Humboldt Stiftung para pesquisadores experientes (setembro de 2018 a outubro de 2019). Integrante do Coletivo Bonobando e do Grupo Pedras de Teatro. E-mail: adriana.schneider@eco.ufrj.br; Instituição filial: Universidade Federal do Rio de Janeiro; País: Brasil. 
Enfim, a coisa dada não é uma coisa inerte. Marcel Mauss, 2003, p.200.

A dádiva deve sempre se mover. Há outras formas de propriedade que ficam paradas, que marcam um limite ou resistem movimento, mas a dádiva segue seguindo. Lewis Hyde, 2007, p.4.

Aqui a coisa será feita a quatro mãos. Este é um texto escrito a quatro mãos. Quatro mãos e tudo dos nossos corpos, as multidões que todos somos, e mais nossas circunstâncias e contextos. E junta-se a nós agora, por meio deste texto, você. E também uma pedra do sertão do Cariri, um ninho de passarinho, um carretel de linha cor de laranja, uma corda de escalada de 60 metros, fios elétricos desencapados, uma narrativa sobre cinco dias vividos em uma aldeia Guarani, uma citação de Roland Barthes, um trecho do filme Copacabana Mon Amour de Rogério Sganzerla, um saco de risada, um elefante inflável na sala de um apartamento em Berlim, o programa da peça Nhanhomoirumba - um panfleto-esquiva, um fio de cabelo branco, um copo de vidro com purpurina dourada quase até a boca, uma instalação do Ricardo Basbaum, a voz da Elza Soares, um toque de lansã, o Divisor de Lygia Pape, o Cruzeiro do Sul de Cildo Meireles, um punhado de palha utilizado por Allan Kaprow em um happening nos anos 80, o projeto Lanchonete $<>$ Lanchonete de Thelma Vilas Boas, páginas selecionadas dos cadernos de Artaud, pinturas rupestres da Serra da Capivara, pensamentos de David Kopenawa, um talão de jogo do bicho, casos de ferida colonial, um martelo, um tijolo, um despacho em Teerã, o marco zero de Brasília, um soco inglês, a frase "ser livre é participar" pichada em um muro, a palavra "impasse", uma caneta formato cenoura com olhos e boca desenhados e mais um topete verde. Estas coisas e mais outras, muitas outras, estão reunidas, agrupadas, ajuntadas neste texto. Encaixadas, penduradas, chacoalhando, como se este artigo fosse uma cacimba de frete de mudança, ou uma mala daquelas tipo baú. Ou não.

Melhor pensar no que aconteceu mesmo, escapar do plano da metáfora desde o princípio, escapar da linguagem que remete, que substitui e propor uma des-metaforização geral. Uma des-metaforização geral. E então, com as palavras, dar a ver uma sala - uma sala com pé direito alto, duas janelas, uma porta, paredes brancas, microfones, duas caixas de som, uma mesa e muitas cadeiras de madeira. Uma sala-auditório num centro de artes no Centro do Rio de Janeiro. Uma sala, as coisas que lá já estavam e mais uma coleção de coisas trazidas. E todos aqueles e aquelas que trou- 
xeram as coisas para partilhar. Muita gente. E também, aquelas e aqueles que vieram para participar da partilha. Muito mais gente ainda.

Era novembro de 2017 e já estava claríssimo. Aliás, há muito tempo a questão se impôs, desde sempre a questão ronda: pensar fora da dimensão coletiva não faria sentido (se é que há possibilidade de pensamento fora do coletivo posto que o pensar é articular; posto que a linguagem é articular; posto que não há nada por si só, nada em si mesmo, fora do movimento). Enfim, pensar em coletivo sobre pensar em coletivo seria nossa busca. Ou ainda, praticar pensamento em coletivo e já estar em ação coletiva seriam nosso ato de buscar.

O encontro internacional arte agora: partilhas de matérias, uma realização do Programa de Pós-Graduação em Artes da Cena da Escola de Comunicação da Universidade Federal do Rio de Janeiro (PPGAC ECo UFRJ), aconteceu nos dias 22, 23 e 24 de novembro de 2017, no Centro Municipal de Artes Hélio Oiticica (CMAHO), um prédio de três pisos construído em 1872 e localizado no Centro do Rio de Janeiro. O evento foi concebido e produzido por Eleonora Fabião, Adriana Schneider, e os 16 participantes convidados foram: Profa. Dra. Ana Kiffer (PUC-Rio), Prof. Dr. André Lepecki (NYU), Prof. Dr. Daniel Castanheira (PUC-Rio), Prof. Dr. Felipe Ribeiro (UFRJ), Flavia Meireles (Doutoranda PPGCOM UFRJ), Profa. Dra. Gabriela Lírio (UFRJ), Dra. Izabela Pucu (Doutora em História e Crítica da Arte PPGAV UFRJ), Prof. Dr. José Fernando Azevedo (EAD-ECA/USP), Profa. Dra. Livia Flores (UFRJ), Profa. Dra. Luiza Leite (pós-doc PPGAC UFRJ), Prof. Dr. Manoel Silvestre Friques (UNIRIO), Dra. Paula Hildebrandt (HafenCity University Hamburg), Prof. Dr. Pablo Assumpção Barros Costa (UFC), Prof. Dr. Ricardo Basbaum (UFF), Profa. Dra. Tania Rivera (UFF), Prof. Dr. Thiago Florêncio (URCA). Ou seja, pessoas de diversas partes do Rio de Janeiro juntaram-se com pessoas do Crato, de São Paulo, Nova York, Fortaleza, Hamburgo e Niterói.

Três verbos guiaram o movimento: partilhar, inspirar e especular. "Partilha" que, na matemática social, é, na verdade, uma operação de multiplicação. "Partilha", modo de produção e de relação que se aproxima de economias da dádiva ao invés de economias comerciais. E aqui a escolha de palavras é importante. Repare que não propusemos uma "troca de matérias", um toma-lá-dá-cá de conteúdos, nem qualquer outro tipo de operação em que todos lucram e acumulam novas posses-saberes. Propusemos uma partiIha, uma divisão multiplicativa, uma distribuição em que dar e receber são mais entendidos como funções orgânicas, básicas para a sobrevivência, do que como investimento e capitalização. Esse era o espírito do evento e seu 
modo mesmo de produção, visto que, como havia pouca verba disponível no Programa e uma necessidade inadiável de encontro naquele momento, com a exceção da compra de duas passagens aéreas nacionais, tudo foi realizado colaborativamente pelas alunas e alunos, professoras e professores, artistas, pesquisadoras e pesquisadores envolvidos. Contamos com hospedagens solidárias, com a comunidade e a infraestrutura do PPGAC UFRJ, com a parceria institucional preciosa do CMAHO e com o rico trabaIho e dedicação de todos.

Fato é que, como membros da academia, inúmeras vezes participamos de eventos sem receber honorários. Talvez, por dois motivos. Porque acreditamos veementemente na importância de contribuir para o desenvolvimento da área e da pesquisa como um todo. E também, por haver um possível retorno em "capital profissional" por meio da divulgação de nossas pesquisas e da promoção de nossas pessoas e instituições. Nesse evento porém, importante dizer, o protagonismo de cada participante era deslocado pelo estímulo ao diálogo entre os componentes das mesas - o protagonismo era do diálogo, da partilha. E, além disso, a costumeira valorização das presenças humanas era radicalmente revista por conta da importância dada aos materiais trazidos por cada um e colocados sobre a mesa (ou em meio a plateia, ou projetados nas paredes, ou espalhados a partir das caixas de som). Estávamos todos empenhados ali em ceder espaço e escutar as matérias.

A proposta de partilhar matérias nos interessa pela percepção de que "na medida em que produzimos objetos acabamos sendo produzidos por eles" ${ }^{\prime}$, e que a performatividade intrínseca deles possibilita a "ativação política da coisa"2. "Coisa" que passa a nomear tanto o "objeto" quando liberado de seu determinismo utilitarista, como o "sujeito" quando liberto de sua egoexistência pessoalista e colonialista. Quando entendidos como coisas, objetos não estão apenas subjulgados a dominação de sujeitos, e sujeitos não serão nunca meros senhores de objetos (e até de si mesmos ou de outros sujeitos). No plano das coisas humanas e não-humanas, de uma "ética da coisa" como propõe André Lepecki, todos os tipos de matérias co-constituem-se.

Neste contexto, a noção de política é compreendida como aquilo que acon-

1 Lepecki, 2012, p.94.

2 Idem, p.98. 
tece no "intra-espaço" entre os humanos "e se estabelece como relação"3. Ou ainda, no intra-espaço relacional entre todas as coisas presentes; na articulação incessante das matérias humanas e não-humanas. Nós, todos e tudo conjuntamente, produzimos a política e ela nos produz. Quem sabe então, a política não seria uma terceira coisa? Justamente a coisa que articula coisas, que articula os antes chamados "sujeitos" e "objetos" para além (e aquém) deles mesmos? Quem sabe, a política seria a coisa secretada nas relações? E, talvez, quem sabe, entender a política como coisa possa nos ajudar a pensá-la e fazê-la? Possa nos ajudar a gerá-la? Quem sabe, a política seja a coisa coletiva por definição (ou indefinição)? A coisa coletiva por excelência (e emergência)? Se assim for, é preciso estarmos mesmo permanentemente atentos aos nossos modos de produção e partiIha política posto que, em um país tão marcado pelo colonialismo como o nosso, os moldes estruturais, as matrizes relacionais mais arraigadas, são profundamente racistas e masculinitas, extrativistas e criminosas, perversas e tristes. Ou seja, no contexto brasileiro, não é preciso apenas fazer políticas anti-coloniais mas agir políticas de-colonizadoras das coisas e como coisa. Coisa sempre em movimento; coisa a ser permanentemente gerada, elaborada e partilhada de acordo com as necessidades e circuntâncias.

Ao longo do encontro arte agora: partilhas de matérias, o que vimos foram as matérias ultrapassando seus sentidos utilitários e ampliando seus agenciamentos para além de uma explicação em si mesmas. Elas funcionaram como condensadoras de sentidos múltiplos: poéticos, etnográficos, sociológicos, memorialistas, psicológicos, históricos, artísticos, éticos, sensoriais, espirituais, políticos, etc. Mas, especialmente, as danças das matérias deslocaram as falas elaboradas pelos palestrantes para um espaço de contato mais relacional, permeado pelas proposições das coisas presentes. Pensava-se ali sobre o fazer político e buscava-se meios de fazer uma política de cunho anti-colonial em meio a tanto e tamanho colonialismo estrutural. Esse encontro foi mesmo uma busca nesta direção.

Além da prática da partilha, a noção de "inspiração" também foi uma orientação. Inspiração que, como a palavra diz, envolve ar e ação e, talvez, quem sabe, seja até um codinome para o fazer artístico, matéria que tanto nos 
ocupa e inspira no PPGAC. Nosso entendimento é que trabalhos de arte formam correntes de inspirações, passagens inspiracionais entre matérias de toda sorte, humanas e não-humanas, que, finalmente, tocam os receptores e os impulsionam a desejar. Também a agir seus desejos. Ou simplesmente a viver. Porque, como sabemos, não basta estar vivo para estar em vida. Trocando em miúdos, em novembro de 2017 já estava claro que precisávamos cuidar de nos inspirarmos mutuamente e, por meio desse encontro, queríamos entender se a prática de partilhar matérias (objetivas e subjetivas) num evento acadêmico poderia ser um modo potente, ser realmente uma fonte de inspiração. Trocando em mais miúdos ainda: imaginamos uma ação performativa, pois nisso somos treinadas, pois essa pode ser uma de nossas contribuições mais significativas como profissionais da área das artes, e convidamos brilhantes pesquisadoras, pesquisadores e artistas, pessoas que muito nos inspiram, para colaborar conosco. Afinal, precisamos estar permanentemente buscando modos adequados para dar passagem às matérias (objetivas e subjetivas) com as quais lidamos.

Quanto à noção de "especulação" e o ato de especular, interessa-nos pensar sobre o pensar. É uma dessas questões constrangedoramente básicas que, por serem tão básicas, raramente nos colocamos: afinal de contas, o que é especular, como se faz? Como o verbo indica, há algo de espelhamento no ato - espelhamento que mostra o mundo, que nos mostra a nós mesmos, que nos mostra no mundo e como mundo, em reciprocidade e coexistência. Espelho que ao mesmo tempo puxa a imagem para si e a lança para fora de si. Que capta e projeta. Uma espécie de pulsação. Uma relação permanente de aproximação e afastamento, de ceder e resistir, escutar e firmar corpo para que se possa pensar; para que se possa ver e se deixar ver em processo de pensamento. Se deixar ver em processo especulativo. Sem a coisa pronta ainda (se é que algum dia algum pensamento fica pronto). Se deixar ficar por um tempo em estado de especulação. Em estado de especulação na frente dos outros (e não no quarto, fechado, só, quando se prepara a fala que deverá ser apresentada como pensamento "pronto"). Como o verbo diz, especular refere-se a estudar, a observar com atenção, meditar, conjecturar. Seria então o especular já uma prática ou algo que antecede uma prática refletida? Nesse evento, apostamos na encenação da especulação como uma prática a ser compartilhada.

Em termos muito objetivos, o encontro consistiu na realização de seis mesas, uma conferência seguida do lançamento de um livro, uma refeição “junta prato" e uma performance. A conferência foi realizada por André Lepecki e mediada por Pablo Assumpção Barros Costa, tradutor do livro de 
Lepecki para o português e cujo lançamento ocorreu na ocasião - Exaurir a Dança: Performance e a Política do Movimento (São Paulo: AnnaBlume, 2016). No meio do encontro, juntamos pratos num almoço coletivo que incluiu o pessoal do CMAHO. E, para finalizar o evento, uma performance de Adriana Schneider e Ana Kiffer, intitulada A Perda de Si - Cartas de Artaud, derivou-se em uma conversa mediada por Gabriela Lírio. As seis mesas realizadas, nosso foco neste artigo, foram compostas por dois/ duas artistas-pesquisadores/as-professores/as e um/a mediador/a cada. As mesas não tinham títulos nem seguiam temas pré-determinados.

Nosso trabalho curatorial foi, conhecendo as pesquisas dos participantes, criar trios que poderiam, de acordo com nossa visão, gerar partilhas inspiradoras e diálogos vibrantes. Fica claro, portanto, que a motivação curatorial foi reunir agentes - humanos e não-humanos - e estimular fricção. Talvez então, uma vez juntos, pudéssemos especular sobre possíveis títulos para cada mesa de acordo com as interlocuções realizadas. Ficava invertida assim a tendência, em eventos acadêmicos, de priorizar a troca de conhecimentos acumulados e pré-formatados por cada palestrante. Incentivou-se o encontro e a criação de sentido dialogicamente. Ficava invertida, também, a tendência de pré-estabelecer temas. Podemos dizer que nosso "quase-tema" era a proposta de partilha. Nos interessava experimentar uma dramaturgia do encontro sustentada pelas ideias de partilha, inspiração e especulação.

Para tanto, foi preciso criar um programa performativo 4 que norteasse a experimentação. Este programa tinha o formato de um convite onde apresentávamos aos participantes as questões de base e os modos de operação do encontro. Assim:

O que partilhar com as/os demais hoje? Quais matérias, pensamentos, histórias, vozes, sensibilidades, conceitos, trabalhos, modos de ação, de relação, de produção?

Seremos 2 artistas-pesquisadores/as-professores/as por mesa, mais 1 mediador/a. Cada artista-pesquisador/a-professor/a deverá levar 5 matérias de sua escoIha para compartilhar com a/o companheira/o de mesa (sons, imagens, objetos, conceitos, textos, gestos, coisas, gentes, o que julgar adequado), matérias que façam

4 A noção de programa performativo vem sendo desenvolvida e praticada por Eleonora Fabião nos últimos 12 anos. Sobre este procedimento composicional ver, por exemplo: FABIÃO, Eleonora. Corpo-em-experiência: o programa performativo In: ILINX, Revista do LUME. Campinas - SP, n. 4, 2013. Disponível em: https://www.cocen.unicamp.br/ revistadigital/index.php/lume/article/view/276 Acesso em: 14 de agosto de 2019. 
parte do seu mundo, do seu repertório de indagações, de trabalho, de pesquisa, coisas do seu interesse no momento, coisas que te inspiram.

Recomenda-se que a/o mediador/a faça uma pesquisa sobre o trabalho dos/as participantes da mesa que mediará - assim, estará mais preparado/a para indagar, associar, lembrar, fazer fluir, girar a roda, ativando a conversa que surgirá do encontro de todas as matérias.

Será partilhado 1 material de cada vez, alternando os participantes. Assim: pessoa 1 apresenta sua matéria 1 e porque decidiu partilhá-la; daí será a vez da pessoa 2 fazer o mesmo; e então será a vez da pessoa 1 trazer seu material 2; e da pessoa 2 apresentar seu material 2 e assim sucessivamente $1.1+2.1+1.2+2.2+1.3+2.3+1.4+2.4+$ $1.5+2.5$.

Será muito bonito para quem assiste conhecer não apenas os materiais escolhidos e suas motivações, mas acompanhar as escolhas de ordem de apresentação de cada coisa - o que possivelmente só poderá ser decidido no momento, a partir das atrações entre as matérias.

Cada mesa tem duas horas de duração - suponhamos que cada apresentação de material dure então 8 minutos em média -8 min. $\times 5$ matérias +8 min. $\times 5$ matérias $=10$ matérias em 80 minutos. Restarão 40 minutos para trocas com a plateia. $O /$ a mediador/a estará infiltrada/o ao longo de todo o tempo. Em resumo: o importante é cada um/a calcular o total de sua apresentação em cerca de 40 minutos.

Este programa é o nosso horizonte.

Ou seja, o chamado era para que cada participante trouxesse o que julgasse necessário partilhar com os demais hoje. Seriam pequenas coleções, arranjos portáteis, matérias para compartir com a sua ou seu companheiro de mesa, elementos que fazem parte do seu universo de pesquisa, coisas que o inspiram e, portanto, poderiam inspirar outros.

O que você levaria para partilhar em um evento como esse hoje? Quais seriam as suas cinco matérias escolhidas e por quê?

Nos pautamos em algumas interrogações que operam como princípios de sociabilidade, de composição e como guia teórico-conceitual: como uma partilha de matérias pode desencadear conversas sobre arte e política hoje? Como a oferta de matérias por um participante, e a sua recepção por outro, pode gerar acontecimento e mover pensamento? Pensamentos indissociáveis do acontecimento-partilha, impensáveis fora desses circuitos relacionais deflagrados pelo ato de partilhar. Pensamentos cultivados num espaço especulativo e dialógico, feitos da articulação entre a pesquisa de um e a pesquisa do outro, por meio da roçadura entre as referências de um e as referências do outro. Como pensamento artístico e conceitual pode ser, de fato, elaborado coletiva, dialógica e presencialmente? E, por fim, muito objetivamente, como programas performativos podem orien- 
tar a organização de eventos científicos na área de artes na busca por outras éticas e dramaturgias para a troca de ideias e experiências? Como criar eventos baseados em programas performativos pode possibilitar a busca por outras cenas acadêmicas? E (mesmo que soe constrangedoramente básico, mais uma vez), para além da intencionalidade dos agentes e da auto-nomeação, o que constitui uma "cena"? O que faz com que um acontecimento seja ou torne-se performativo?

Alguns elementos importantes para aumentar a vibração performativa de um evento seriam: corpos comprometidos e atenção afiada; porções combinadas de previsibilidade e de imprevisibilidade, de estrutura e de soltura; de elaboração de sentido, suspensão de sentido e sensação. Não exatamente um espaço de falas e escutas, mas de atos de fala e atos de escuta. De ações verbais que escutamos com o corpo todo. Ações verbais e não-verbais que impregnam. Essa é a eletricidade do acontecimento performativo, a voltagem daquilo. E nosso momento de gravíssima crise sociopolítica, de destruição, de sucateamento, de desmanche, exige que aprendamos com a energética performativa a articular pensamento e ação de forma inextrincável. Em cena, não há tempo de pensar e tempo de agir, não há "lacuna" entre uma coisa e outra, há corpos comprometidos com passagem e geração de sentidos em coletivo. Esse é o tipo de inteligência em questão. $E$, acreditamos, é desse tipo de inteligência que precisamos. Mas seria então toda performance fundamentalmente um ato de partilha?

Em toda partilha algo se parte e esta partida nos parece fundamental. Há um impacto, uma quebra, um despedaçar, um tanto de impulso e de momento, um tipo de força no ato que consideramos muito importante. Não há convívio político e artístico sem dissonância e impacto (seja em que grau for), sem que algo se parta para que outro algo se componha; sem que algo parta para que outro algo chegue. As partilhas. As partintes e partilhantes partilhações.

Quanto ao contexto daquele evento, daquele evento-hipótese, evento-experimentação, evento-performance, a descrição é suscinta: já em fins de 2017 o quadro era de grave crise política e de violência demente contra a arte e a cultura no país. Basta lembrar que cerca de dois meses antes, a performance La Bête de Wagner Schwarz apresentada no $35^{\circ}$ Panorama da Arte Brasileira no MAM-SP, por conta de um vídeo descontextualizado que viralizou nas redes sociais, havia gerado reações extremamente violentas e calúnias criminosas com desdobramentos legais e políticos estapafúrdios. Nunca poderemos esquecer: curador e artista, Luiz Camillo Osorio e 
Wagner Schwarz, foram intimados a depor na Comissão Parlamentar de Inquérito de Maus-Tratos do Senado Federal, CPI que investiga irregularidades e crimes relacionados a maus tratos em crianças e adolescentes no país. O descabimento e a distorção dos fatos atingiram proporções assombrosas. Uma experimentação artística foi inescrupulosamente difamada para benefício político de grupos conservadores. Precisávamos, portanto, nos reunir e refletir sobre a nossa cena contemporânea. Refletir sobre a cena experimental fazendo cena experimental. Não poderíamos nos restringir a "falar sobre", a tratar teoricamente temas da arte contemporânea, seus comos, ondes e porquês. Era (e é) preciso falar fazendo e fazer falando.

Ou seja, o velho debate, e frágil embate, entre teoria e prática, também se apresentava como questão de fundo no evento. As pesquisas na área de artes têm avançado no entendimento de que as opções metodológicas específicas a cada projeto investigativo dão respostas contundentes às tensões entre teoria e prática. O processo de legitimação de artistas-pesquisadores em universidades no Brasil e no exterior nos últimos anos é exemplar nesse sentido (sendo o PPGAC da UFRJ especificamente dedicado à formação de artistas-pesquisadores em uma de suas linhas de pesquisa). Mesmo com estes avanços, a necessidade argumentativa de que as relações entre teoria e prática são indissociáveis ainda se faz presente. Isso acontece especialmente nos momentos em que a área se confronta com os mecanismos e procedimentos acadêmicos e científicos hegemônicos e tomados como referência de práxis em outras áreas de conhecimento. Este contrassenso, que gera impasses, desigualdades orçamentárias entre as áreas e parâmetros que norteiam falsas hierarquias, acaba por engessar modos de produção e difusão de conhecimento em formatos que não atendem às especificidades das artes. Lembremos que, já em 1968, mais de 50 anos atrás, enquanto trabaIhava em projetos para a alfabetização de adultos em zonas rurais do Chile, Paulo Freire escreveu seminários que entrelaçavam as relações entre prática e teoria de forma eficaz para a superação destas dicotomias.

Não é estranho, portanto, que os verbalistas se isolem em suas torres de marfim $e$ considerem desprezíveis os que se dão à ação, enquanto os ativistas considerem os que pensam sobre a ação e para ela, como "intelectuais nocivos", "teóricos" e "filósofos" que nada fazem senão obstaculizar sua atividade. Para mim, que me situo entre os que não aceitam a separação impossível entre prática e teoria, toda prática educativa implica numa teoria educativa. ${ }^{5}$ 
Escutamos Paulo Freire para pensar sobre como realizar eventos acadêmicos que possam dar conta das especificidades e complexidades da área das artes. Acreditamos que a criação artística e o pensamento sobre criação artística abrem espaços de imaginação política e dimensões de sociabilidade extremamente importantes em tempos de crise. A conjuntura atual, nacional e internacional, requer processos de revisão e recriação subjetivos e objetivos urgentes. São tempos que exigem a suspensão de modelos estabelecidos e a busca por modos de criação, relação e produção condizentes com as novas circunstâncias históricas. Metidos como estamos, até o último fio dos cabelos, numa crise de escala planetária marcada pelo crescimento e fortalecimento da extrema direita e a destruição do ecosistema, questionamos: que perguntas e respostas a arte pode oferecer à crises sociais, ecológicas, políticas? É possível analisar contextos políticos e interferir por meio das artes? Que papéis a arte vem desempenhando nesse momento crítico? Que papéis queremos que a arte desempenhe? O que queremos que arte seja e mova agora? Artistas e pesquisadores de arte estão particularmente instrumentalizados para, a partir dessas questões, propor encaminhamentos. Contradizendo a imagem senso-comum da arte como uma espécie de elemento decorativo, ou como "reflexo do seu tempo", a arte contemporânea se coloca como um espaço de ação poético-política, como agente propositivo. A um só tempo laboratório de experimentação e modo direto de intervenção, muitos artistas contemporâneos entendem seus trabalhos como modos de ação poético-política no mundo e para a geração de mundos.

Também no âmbito acadêmico propriamente dito, estamos enfrentando a necessidade de mudanças e nos questionando: que perguntas e respostas a pesquisa em artes pode oferecer? Como nossas práticas de investigação e seus espaços de exercício, avaliação e transmissão em geral (incluindo bancas, salas de aula, reuniões, etc. e não apenas eventos extensionistas abertos ao público em geral) podem ser percebidos e vivenciados como cena, "cena" em suas plenas potências? Como nossas atividades podem ser pensadas e dinamizadas com os dispositivos, processos e experiências de criação e produção que discutem e analisam? Como parar de importar de outras áreas formatos, modelos, critérios, tabelas de pontuação e descobrir os procedimentos de pesquisa, ensino e circulação de conhecimento que melhor revelam as matérias artísticas? Claro, há co-incidências e equi-valências entre campos de conhecimento mas, com certeza, são muitas as especificidades a serem valorizadas.

Talvez então, revisando um pensamento colocado acima, possamos dizer 
que havia sim um tema inervando o encontro internacional arte agora: partilhas de matérias. Quando as circunstâncias são muito graves e as necessidades de transformação evidentes, elas tornam-se matéria em questão e motivação do debate, seja de forma explícita ou implícita. Ou, dito de outra maneira, a partilha da matéria contextual, para não ficarmos doentes de raiva, de tristeza ou de medo, deveria ser feita coletivamente e com o reforço das semânticas e das energéticas cênicas; deveria ser feita coletivamente e com forte energia performativa. Fizemos o que precisávamos fazer. Partilhamos cena acadêmica coletiva na cidade do Rio de Janeiro em novembro de 2017.

Como espectadoras desse evento podemos dizer que um fenômeno nos surpreendeu. Tomara que isso fique claro por meio desta escrita. A sensação como espectadoras era de que também praticávamos o papel de mediadoras. A espontaneidade era tamanha, uma espécie de voluptuosidade sensorial e perceptiva estava tão ativada pelas matérias combinadas e pela combinação das matérias, a flexibilidade daquela cena era tanta, que a responsabilidade de mediação transbordava da mesa para a plateia. A "respondibilidade" estava aguçada. Estava lá um chamamento das coisas. Cabia a todos e todas presentes tecer articulações sobre aqueles acontecimentos inesperados e surpreendentes - como quando dois pesquisadores de uma mesma mesa trazem coisas que se encaixam perfeitamente, ou se encaixam estranhamente, ou quase coincidem, ou contradizem-se, ou dependem de nossa articulação para, de alguma forma, articularem-se. Ou não. Deixa estar. Deixa a coisa coisar. Deixa as coisas coisarem. O tempo trabalhar.

\begin{abstract}
Investir em coisas, não como substitutos do corpo, nem como elementos significantes ou representativos de uma narrativa, mas como parceiros, como entidades co-extensivas no campo da matéria, é ativar uma mudança fundamental na relação entre objetos e seus efeitos estéticos (na dança, no teatro, nas artes visuais, na performance e na instalação). Esta mudança corresponde à ativação política da coisa, para que esta possa fazer aquilo que de melhor faz: despojar objetos e sujeitos de suas armadilhas chamadas "dispositivo", "mercadoria", "pessoa" e "eu".6
\end{abstract}

No encontro, o agenciamento das matérias possibilitou a produção do que poderíamos chamar de dramaturgias, em seu sentido expandido, elaboradas previamente por cada participante na escolha das matérias e na estruturação da fala. No entanto, uma outra dramatugia era criada 
por contato, entre as sequências de matérias, no próprio instante das apresentações, afetando também a atitude de espectação do publico do evento. As relações entre estrutura e momento, entre proposiação e ação do programa performativo, foram fundamentais para o que era apresentado nas mesas, o acontecimento. Este "intra-espaço" criado pela fricção das matérias possibilitou a produção de um outro tipo de presença no espectador, ampliando a escuta de uma fala para outras sensorialidades, conexões, sentidos. Outra vez: as figuras dos espectadores e dos mediadores acabaram por aproximar-se uma vez que cabia a todos os presentes, sem exceção, operar as costuras entre os elementos que paulatinamente eram apresentados e articulavam-se. Todos compúnhamos juntos o acontecimento-pensamento que se dava ali, entre todas as coisas, humanas e não-humanas. Entender e praticar "espectação" como mediação num encontro acadêmico, possivelmente, foi a experiência mais inesperada e impactante do encontro internacional arte agora: partilhas de matérias.

Talvez, estes outros estados de aprendizagem, escuta, espectação e participação tenham relação com o aspecto arcaico da economia da dádiva da qual trata Marcel Mauss em seu Ensaio sobre a dádiva, movido pela pergunta: "Que força existe na coisa dada que faz que o donatário a retribua?"7. O sentido da partilha, que constitui um princípio básico para a vida comum em todas as sociedades, seria a própria política, que ele chama de

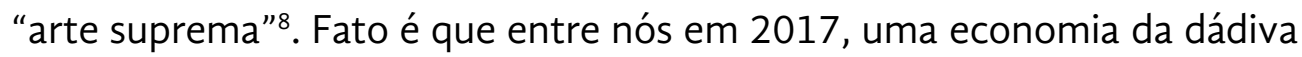
de fato se deu, não simplesmente porque os participantes não recebiam honorários para oferecer suas matérias e o público não pagava ingressos para participar da ação, mas porque o compartir, em si, era nosso tema, nossa dramaturgia e nossa ético-política.

Estamos chegando ao fim dessa partilha mas uma lembrança cruza nossa mente e é preciso colocá-la. Foi em 1975 que Lygia Clark, junto com seus alunos da Sorbonne, realizou Cabeça Coletiva. Uma grande estrutura de madeira compartimentada foi encaixada na cabeça e apoiada nos ombros de um dos participantes. Os demais membros do coletivo "serviam" aos passantes nas ruas as inúmeras coisas (sapatos, frutas, cartas de amor, dinheiro, etc.) que estavam encaixadas nos compartimetos da estrutura. A "cabeça" ficou na casa de Lygia ao longo das semanas anteriores e as maté-

7 Mauss, 2003, p.188.

8 Idem, p.314. 
rias foram sendo colocadas aos poucos, como pensamentos cultivados, até o dia em que o grupo se reuniu para sair pelas ruas de Paris e partilhar a coleção. Aqui também não nos parece haver metáfora alguma. Metonímia, talvez, se pensarmos nisso tudo que metemos em nossas cabeças coletivas e que sai de nossas cabeças coletivas.

Outro caso querendo ser partilhado. O ceramista Edmund de Waal (2011) escreveu a história de 264 netsuquês, minúsculas esculturas japonesas figurativas feitas em marfim, pedras semi-preciosas ou madeira, que herdou de sua família de origem judaica. A história da coleção, formada por Charles Ephrussi, seu tio tataravô, e que consiste na história da sua própria família, é também um ponto de vista historiográfico da questão judaica na Europa, de meados do século XIX ao nazismo. Os netsuquês que restaram de uma imensa coleção de arte, foram ignorados pelos nazistas. Eles sobreviveram porque foram escondidos um a um, cuidadosamente, pela criada Anna, dentro do colchão de sua cama.

A relação que Waal constituiu com estes objetos, é também inspiradora para nossas intenções com as partilhas de matérias. Os netsuquês não são apenas disparadores do imaginário ficcional, mas coisas-testemunhas, coisas portadoras de vivências e capazes de reverberações e articulações muito concretas. Mais uma vez, a relação não é metafórica, alegórica ou figurada.

Não tenho direito à nostalgia por toda essa riqueza e glamour perdidos de um século atrás. E não estou interessado em nada rarefeito. Eu quero saber qual a relação entre este objeto de madeira que giro entre meus dedos - duro, surpreendente e japonês - $e$ os lugares onde ele esteve. Quero ser capaz de entrar em cada cômodo onde este objeto viveu, de sentir o volume do espaço, de conhecer os quadros nas paredes, de saber como era a luz que vinha das janelas. E quero saber em quais mãos esteve, e o que elas achavam e pensaram sobre ele - se pensaram sobre ele. Quero saber o que este objeto testemunhou. ${ }^{9}$

E mais uma última lembrança nos ocorre, ainda uma outra matéria a ser partilhada entre nós para então nos despedirmos. Trata-se de um projeto artístico, de uma situação vivenciada recentemente. Era março de 2019 e Eleonora Fabião foi convidada para realizar uma ação no Museu do Louvre Pau-Brazyl - projeto de ocupação artística de um prédio modernis- 
ta chamado Louvre e seus arredores no Centro da cidade de São Paulo ${ }^{10}$. Em resposta ao convite, Eleonora imaginou uma mesa a ser posicionada no térreo do prédio - num lugar reservado, fora da passagem, embaixo de escadas rolantes, no caminho para os elevadores sociais - e escreveu o projeto no formato de uma carta endereçada a todos os condôminos (moradores e comerciantes com lojas no pequeno shopping que ocupa os dois primeiros andares desse Louvre brasileiro). No projeto-carta, a performer explicava sua proposta:

A coisa é simples. Às vezes temos coisas em casa que não usamos mais. Ou até coisas que usamos e gostamos, mas que talvez estivessem melhor em outra casa. Então, o meu convite para você é o seguinte: repasse essa coisa, leve ela para viver uma outra vida. A M.E.S.A. é o lugar onde você poderá deixá-la para que uma vizinha ou vizinho a encontre; e a M.E.S.A., é o lugar onde você encontrará coisas deixadas por seus vizinhos e vizinhas. [...] você poderá ver se algo que lá está te chama. Se te chamar e vocês se entenderem, se você quiser subir com a coisa e a coisa quiser seguir contigo, basta pegar e levar para a sua casa. [...] Esse é o convite. A ação começa quando for deixada a primeira coisa. E a ação se conclui quando vocês, pessoas e coisas moradoras do Louvre decidirem que é chegado o fim. [...] E veremos como a coisa se desdobra - talvez em algum momento histórias precisem ser repassadas, pessoas queiram visitar coisas, coisas queiram visitar pessoas, pessoas queiram conhecer pessoas, algumas coisas desejem permanecer mais um tempo juntas na M.E.S.A.. Veremos. E escutaremos as necessidades.

Quase no final da carta, antes de despedir-se, esclarece a sigla:

M.E.S.A. - Movimento Expandido de Solidariedade Articulada

M.E.S.A. - Matéria Espessa e Suporte Ativo

M.E.S.A. - Micro Espaço Sensível e Aberto

M.E.S.A. - Manobra de Escuta Supra Antenada

M.E.S.A. - Modo Energético de Sociabilidade Atenciosa

M.E.S.A. - Massa Elíptica de Significados Alternantes

M.E.S.A. - Movida Extremamente Simples e Animada

10 O Museu do Louvre Pau-Brazyl foi idealizado pelos curadores Jéssica Varrichio e Guilherme Giufrida, e vem sendo desenvolvido em colaboração com diversos artistas desde 2016 por meio de diferentes eventos. Para mais informações sobre o projeto ver: https://www.louvrepaubrazyl.org/

Acesso em: 23 de setembro de 2019. 
Pois fato é que o síndico do prédio e a comissão condominial, sem apresentar qualquer justificativa, vetaram a proposta. Os curadores, que também são moradores do Louvre, tentaram negociar reduzindo o projeto a um mês, depois a uma semana e, finalmente, restringindo a ação a um único dia. Nada. Explicaram que iriam responsabilizar-se inteiramente por qualquer acontecimento ou repercussão. Nada. Solicitaram então, a pedido da artista, a apresentação dos motivos da recusa por escrito, em uma carta-resposta ao projeto. Nada. Nada de nada. Não houve espaço para nenhum tipo de diálogo, não houve interesse em partilhar qualquer matéria. Nada e ponto. Assim foi. Assim é. Fim. Fim de papo sem que qualquer conversa tenha sido sequer iniciada. Diante do fato, conclui-se que partilhar não é coisa nada simples em se tratando do senso comum. Conclui-se, que a economia da dádiva, de fato, contradiz os valores vigentes - as forças neoliberais, necro-liberais, a neura-libertina, a lógica do capital. Foi significativo compreender que, nem como "performance artística", a economia da dádiva poderia estabelecer-se. Ou, talvez, a comissão condominial tenha entendido que uma "mera performance artística" é já a proposição e a realização de uma forma de vida. Se assim foi, são pessoas muito perspicazes, entenderam tudo muito bem entendido e, por isso mesmo, impediram a experimentação. Afinal, já pensou se a coisa pega? Já pensou se as coisas começam sua coisação pelo prédio afora? Pela cidade afora? Já pensou se a dádiva vira uma opção ao consumo na cidade de São Paulo? Se as coisas humanas e não-humanas emancipam-se umas às outras com uma força de-colonizadora irrefreável? Numa onda irreversível? Já pensou? Já pensou se o dinheiro, por exemplo, vira uma coisa entre outras coisas e deixa de ser uma religião ou um vício, um senhor ou um capataz? A casa cai.

Contamos brevemente essa história porque, desde seu impedimento, tornou-se fundamental fazer com que essa performance aconteça de alguma forma. Que a M.E.S.A. aconteça ao menos aqui, neste suporte. Partilhar essa história é fazer com que a-peça-que-não-aconteceu aconteça como narrativa e assim reverbere, repercuta. Ou ainda, talvez o fato dela não ter podido acontecer seja o acontecimento em si. A impossibilidade de realização da peça é a peça. E o local de acontecimento dela passou a ser aqui, partilhando-a. Além disso, o seu impedimento aponta com clareza a necessidade de realizarmos muitos eventos (acadêmicos, artísticos, comunitários) entendidos e vivenciados como partilhas. A ênfase na partiIha, longe de ser um maneirismo artístico, é uma atitude composicional ético-política. 
Agora sim, afinal, estamos chegando ao fim dessa partilha. No caso do encontro internacional arte agora: partilhas de matérias, diferentemente da Cabeça Coletiva (onde Lygia Clark e colaboradores partilharam matérias nas ruas de Paris dos anos 70), diferentemente das histórias de Edmund de Waal, sua família judaica e seus 264 netsuquês japoneses (que sobreviveram a duas Grandes Guerras Mundiais e ao nazismo escondidos num colchão), e diferentemente do projeto M.E.S.A. (cuidadosamente concebido porém irrealisável num edifício histórico de classe média paulistana em fins da segunda década do século XXI), as matérias trazidas pelos participantes foram levadas para dentro do $\mathrm{CMAHO}$ e ali partilhadas. Algumas das coisas até ficaram por lá, como a purpurina dourada agora encrustrada no rodapé. Outras voltaram para suas casas, como a caneta de cenoura, herança deixada pela mãe de um dos participantes. Outras foram ofertadas, como o fio de cabelo branco que Adriana deu para Eleonora (que o comeu ali mesmo). Porém, fato é, e sem metáforas, que todas as coisas partilhadas naqueles dias entranharam em nossos corpos - a voz da Elza Soares, as imagens do cinema marginal de Sganzerla, as pinturas rupestres da Serra da Capivara, a pedra do Cariri ou o entendimento de esquiva como forma de combate dos Guarani. Todas, com certeza, de uma maneira ou de outra, tornaram-se também nossas pois passaram a nos inspirar a partir dali. Todas ganharam as ruas e os campos e as casas e as salas de aula e os mais diversos espaços, virtuais e atuais, que passamos a ocupar desde ali.

Cabeças coletivas dormem sobre trouxas de coisas partilhadas para sonhar múltiplo.

Cabeças coletivas sonham grande, agem junto e pensam longe. Cabeças coletivas calçam sapatos como chapéus. 


\section{Bibliografia:}

ARENDT, Hannah. O que é política? In: O que é política? - fragmentos de obras póstumas. Rio de Janeiro: Bertrand Brasil, 1998.

FREIRE, Paulo. Ação cultural para a liberdade: e outros escritos. Rio de Janeiro: Paz e Terra, 1981.

HYDE, Lewis. The Gift: creativity and the artist in the modern world. New York: Vintage Books, 2007.

LEPECKI, André. 9 variações sobre coisas e performance. In: Urdimento, Florianópolis, n. 19, p. 95-101, nov. 2012.

MAUSS, Marcel. Ensaio sobre a Dádiva: forma e razão da troca nas sociedades arcaicas. In: Sociologia e Antropologia. São Paulo: Cosac \& Naify, 2003.

WAAL, Edmund de. A lebre com olhos de âmbar. Rio de Janeiro: Intrínseca, 2011. 